\title{
A tumor microenvironment-responsive poly(amidoamine) dendrimer nanoplatform for hypoxia-responsive chemo/chemodynamic therapy
}

Yingchao Hao, Yue Gao, Yu Fan, Changchang Zhang, Mengsi Zhan, Xueyan Cao, Xiangyang Shi ${ }^{*}$ and Rui Guo* (1)

\begin{abstract}
Background: Chemodynamic therapy is a promising cancer treatment with specific therapeutic effect at tumor sites, as toxic hydroxyl radical $(\cdot \mathrm{OH})$ could only be generated by Fenton or Fenton-like reaction in the tumor microenvironment (TME) with low pH and high level of endogenous hydrogen peroxide. However, the low concentration of catalytic metal ions, excessive glutathione (GSH) and aggressive hypoxia at tumor site seriously restrict the curative outcomes of conventional chemodynamic therapy.

Results: In this study, polyethylene glycol-phenylboronic acid (PEG-PBA)-modified generation 5 (G5) poly(amidoamine) (PAMAM) dendrimers were synthesized as a targeted nanocarrier to chelate $\mathrm{Cu}(\mathrm{II})$ and then encapsulate hypoxia-sensitive drug tirapazamine (TPZ) by the formation of hydrophobic Cu(II)/TPZ complex for hypoxiaenhanced chemo/chemodynamic therapy. The formed G5.NHAc-PEG-PBA@Cu(II)/TPZ (GPPCT) nanoplatform has good stability and hemocompatibility, and could release Cu(II) ions and TPZ quickly in weakly acidic tumor sites via $\mathrm{pH}$-sensitive dissociation of $\mathrm{Cu}(\mathrm{II}) / \mathrm{TPZ}$. In vitro experiments showed that the GPPCT nanoplatforms can efficiently target murine breast cancer cells (4T1) cells overexpressing sialic acid residues, and show a significantly enhanced inhibitory effect on hypoxic cells by the activation of TPZ. The excessive GSH in tumors could be depleted by the reduction of $\mathrm{Cu}(\mathrm{II})$ to $\mathrm{Cu}(\mathrm{I})$, and abundant of toxic $\cdot \mathrm{OH}$ would be generated in tumor cells by Fenton reaction for chemodynamic therapy. In vivo experiments demonstrated that the GPPCT nanoplatform could specifically accumulate at tumors, effectively inhibit the growth and metastasis of tumors by the combination of CDT and chemotherapy, and be metabolized with no systemic toxicity.
\end{abstract}

Conclusions: The targeted GPPCT nanoplatform may represent an effective model for the synergistic inhibition of different tumor types by hypoxia-enhanced chemo/chemodynamic therapy.

Keywords: Tumor microenvironment-responsive, Chemodynamic therapy (CDT), Tirapazamine (TPZ), Synergistic therapy, PAMAM dendrimer

\footnotetext{
*Correspondence: xshi@dhu.edu.cn; ruiguo@dhu.edu.cn

State Key Laboratory for Modification of Chemical Fibers and Polymer

Materials, Shanghai Engineering Research Center of Nano-Biomaterials

and Regenerative Medicine, College of Chemistry, Chemical Engineering

and Biotechnology, Donghua University, Shanghai 201620, China
}

(c) The Author(s) 2022. Open Access This article is licensed under a Creative Commons Attribution 4.0 International License, which permits use, sharing, adaptation, distribution and reproduction in any medium or format, as long as you give appropriate credit to the original author(s) and the source, provide a link to the Creative Commons licence, and indicate if changes were made. The images or other third party material in this article are included in the article's Creative Commons licence, unless indicated otherwise in a credit line to the material. If material is not included in the article's Creative Commons licence and your intended use is not permitted by statutory regulation or exceeds the permitted use, you will need to obtain permission directly from the copyright holder. To view a copy of this licence, visit http://creativecommons.org/licenses/by/4.0/. The Creative Commons Public Domain Dedication waiver (http://creativeco mmons.org/publicdomain/zero/1.0/) applies to the data made available in this article, unless otherwise stated in a credit line to the data. 


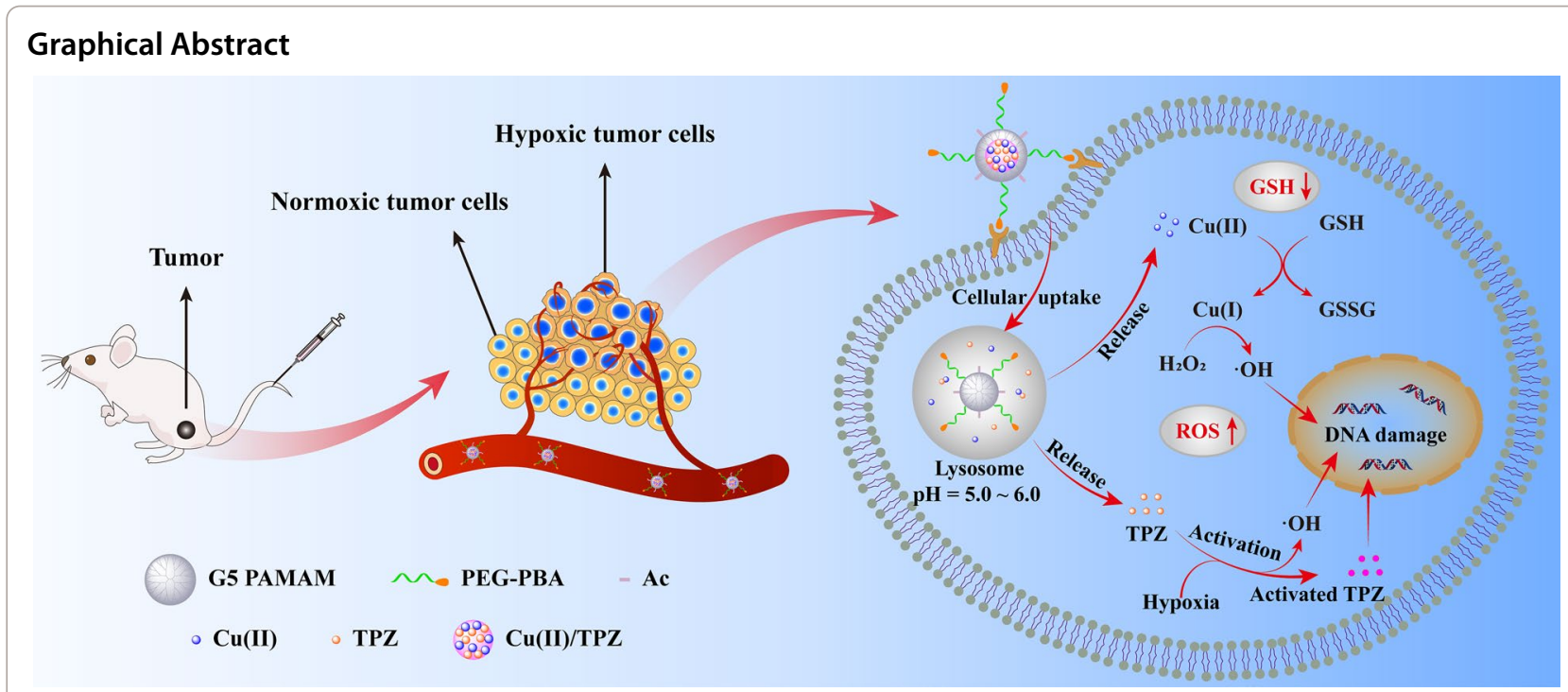

\section{Introduction}

Tumor microenvironment (TME) is characterized by weak acidity, high concentration of hydrogen peroxide $\left(\mathrm{H}_{2} \mathrm{O}_{2}\right)$, excessive glutathione $(\mathrm{GSH})$, and hypoxia [1-3]. It has been well proved that TME not only plays an important role in the occurrence, development and metastasis of tumors $[4,5]$, but also induces resistance to conventional anticancer treatments such as radiotherapy and chemotherapy, resulting in poor prognosis $[5,6]$. Nevertheless, TME could also be exploited to realize certain specific cancer treatments owing to its notable difference to normal tissues [7]. In addition, normalization of TME may in turn improve tumor therapy outcome [4]. Thereby a large number of TME-responsive cancer treatment strategies have been developed in recent years [8-10], including chemodynamic therapy (CDT) [11-13] and hypoxic-sensitive chemotherapy $[14,15]$.

CDT is known as an emerging ROS (reactive oxygen species)-mediated cancer treatment based on in situ Fenton reaction at tumor sites [3]. In a typical CDT, transition metal ions, such as $\mathrm{Fe}(\mathrm{II})[16,17], \mathrm{Cu}(\mathrm{I})[11-13]$ and $\mathrm{Mn}$ (II) [18], are introduced to tumor sites, and highly toxic hydroxyl radicals $(\cdot \mathrm{OH})$ are generated by catalyzing the excess endogenous $\mathrm{H}_{2} \mathrm{O}_{2}$ at TME via Fenton or Fenton-like reaction [2]. CDT could specifically lead to tumor cell death and show neglectable toxicity to normal tissues due to their low $\mathrm{H}_{2} \mathrm{O}_{2}$ level and neutral $\mathrm{pH}$. Various nanoplatforms have been developed to deliver catalytic ions to tumors [19], such as amorphous iron nanoparticles (NPs) [16], ferrous-cysteine-phosphotungstate NPs [17], self-assembled copper-amino acid NPs [11], copper peroxide nanodots [12], nanocatalytic $\mathrm{Cu}-$ GSSG NPs [13], Mn-Cu bimetallic nanocomplexes [18], etc. Among them, $\mathrm{Cu}(\mathrm{II})$ has attracted increasing attention as the CDT catalyst, since the elevated level of GSH in TME could be depleted by the reduction of $\mathrm{Cu}(\mathrm{II})$ to $\mathrm{Cu}(\mathrm{I})[18,20]$, and $\mathrm{Cu}(\mathrm{I})$ possesses a 160 times higher catalytic efficiency than $\mathrm{Fe}(\mathrm{II})$ under the weak acidic condition, leading to effective killing of tumor cells [21-23]. For instance, Ma et al. [11] synthesized copper-amino acid nanoparticles ( $\mathrm{Cu}$-Cys NPs) and demonstrated the excessive GSH and $\mathrm{H}_{2} \mathrm{O}_{2}$ in TME may activate and reinforce the chemodynamic therapeutic effect. Fan et al. [24] synthesized pyridine (Pyr) modified generation 5 (G5) poly(amidoamine) (PAMAM) dendrimer to complex $\mathrm{Cu}(\mathrm{II})$, and proved that the formed hybrid nanoplatform G5.NHAc-Pyr/Cu(II) could display an enhanced inhibition of tumor proliferation and metastasis with the combination of radiotherapy. Despite various successes reported on CDT, the actual efficacy of CDT alone is often limited due to the lack of adequate concentration of catalytic ions at tumors and the low Fenton reaction catalytic activity under hypoxia condition [25-27], and hence combination therapy will be beneficial complement to cancer treatment.

Hypoxia is a common and unique feature of malignant solid tumors $[1,2]$, which may promote the tumor metastatic progression and weaken the traditional chemotherapeutic effects [6]. Among various drugs, hypoxiaactivated prodrugs are of particular interest [28], because they can be converted to potent anticancer drugs through specific reductase in hypoxic cells [25, 29] and effectively kill hypoxic tumor cells within malignant solid tumors $[27,30]$. It is reasonable to speculate that the combination of hypoxia-sensitive chemotherapy and CDT may enhance the antitumor efficacy to hypoxia tumors and 


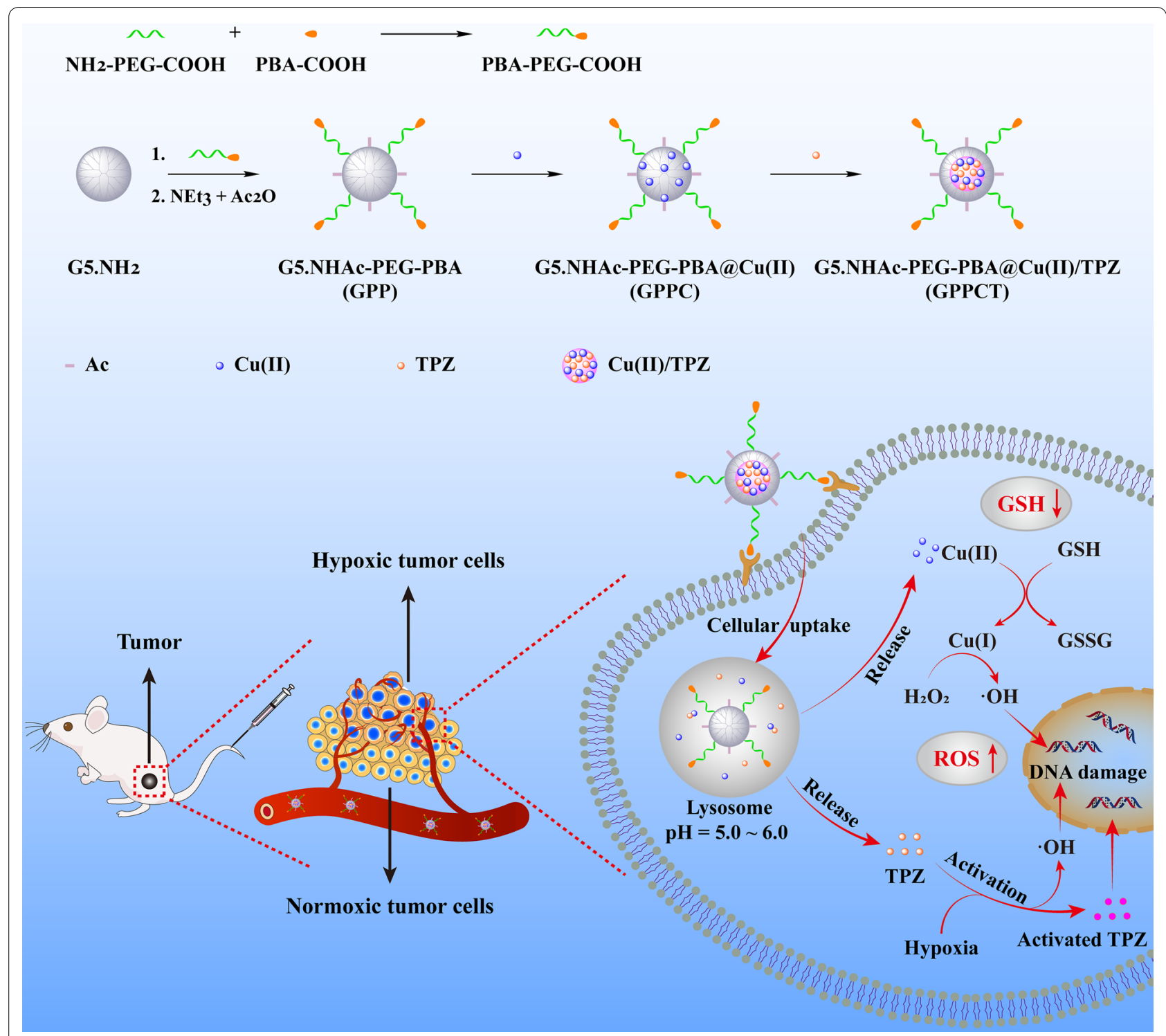

Scheme 1 Schematic illustration of the synthesis of G5.NHAc-PEG-PBA@Cu(II)/TPZ (GPPCT) and the corresponding therapeutic mechanisms against tumor cells

result in the cooperative enhancement in tumor inhibition [31, 32]. As the lead compound in benzotriazine-di$\mathrm{N}$-oxide class of hypoxic cytotoxins, tirapazamine (TPZ) may undergo two different types of breakage reactions in hypoxic tumor cells to produce $\cdot \mathrm{OH}$ and benzotriazinyl (BTZ) radical, inducing DNA strand breakage and topoisomerase II poisoning (Additional file 1: Fig. S1) $[14,26]$. In recent work, Wang et al. [14] synthesized ferrocene-containing polymersome nanoreactors to load TPZ and glucose oxidase, and demonstrated that TPZ could be activated at hypoxic tumors and synergistically inhibit tumors with $\cdot \mathrm{OH}$ generated through Fenton reaction by ferrocene. Therefore, it is highly desirable and challenging to integrate $\mathrm{CDT}$ and hypoxia-sensitive chemotherapy into one nanoplatform, which can specifically deliver CDT catalyst and hypoxia-sensitive drugs to tumor sites, promote drug release and uptake by tumor cells, and exert both therapies specifically within tumors to obtain synergistic therapeutic effect.

Herein, as shown in Scheme 1, we synthesized a targeted nanocarrier based on polyethylene glycol-phenylboronic acid (PEG-PBA) modified PAMAM dendrimers to chelate copper ions firstly, and then load TPZ in dendrimers via the formation of hydrophobic $\mathrm{Cu}(\mathrm{II}) / \mathrm{TPZ}$ complexes. Due to the specific interaction between PBA and the sialic acid residues overexpressed on tumor cells, 
the obtained G5.NHAc-PEG-PBA@Cu(II)/TPZ (GPPCT) nanoplatform can be preferably enriched in tumor site, and rapidly release $\mathrm{Cu}(\mathrm{II})$ and TPZ at the weakly acidic TME by the $\mathrm{pH}$-responsive dissociation of $\mathrm{Cu}$ (II)/TPZ complexes. Then $\mathrm{Cu}$ (II) may be reduced to $\mathrm{Cu}$ (I) by the excessive GSH in tumor cells, and produce toxic $\cdot \mathrm{OH}$ by Fenton-like reaction with endogenous $\mathrm{H}_{2} \mathrm{O}_{2}$. At the same time, the released TPZ may produce BTZ radical and $\cdot \mathrm{OH}$ in tumor hypoxic region, inducing the synergistic effect of chemotherapy and chemodynamic therapy. In addition, GPPCT nanoplatform could decrease the tumor metastasis and show low systemic toxicity. Thus, the designed TME-responsive GPPCT nanoplatform could specifically and effectively eliminate tumors by the synergistic chemodynamic therapy and hypoxiaenhanced chemotherapy, representing an efficient and safe strategy for tumor therapy.

\section{Results and discussion}

\section{Synthesis and characterization of G5.NHAc-PEG-PBA@} $\mathrm{Cu}(\mathrm{II}) / \mathrm{TPZ}$ (GPPCT)

In this study, G5.NHAc-PEG-PBA (GPP) nanocarriers targeting cancer cells overexpressing sialic acid residues were firstly synthesized by conjugating 4-carboxylphenylboronic acid (PBA) onto G5 dendrimer with a PEG chain spacer and then acetylation of remaining amino groups on surface. The structure of GPP was confirmed by ${ }^{1} \mathrm{H}$ NMR spectra in Fig. 1a. The presence of the characteristic peak of PBA at 7.60-7.78 ppm, PEG at $3.61 \mathrm{ppm}$, and acetyl groups at $1.88 \mathrm{ppm}$ indicated the successful synthesis of GPP. By integral calculation, each GPP possessed about 6.8 PEG, 2.9 PBA and 73.3 acetyl groups (Additional file 1: Figs. S2a, b). As a non-targeted control, G5.NHAc-mPEG (GmP) (Additional file 1: Fig. S3) with an average of $7.0 \mathrm{mPEG}$ and 74.3 acetyl groups was synthesized by conjugating $m \mathrm{PEG}$ on the surface of G5 (Additional file 1: Fig. S2c, d). Then, $\mathrm{Cu}(\mathrm{II})$ was complexed into the dendrimers by the tertiary amine groups, and TPZ molecules were loaded via the formation of hydrophobic $\mathrm{Cu}$ (II)/TPZ nanocomplexes to yield G5.NHAc-PEG-PBA@Cu(II)/TPZ (GPPCT) and G5.NHAc-mPEG@Cu(II)/TPZ (GmPCT). UV-Vis spectra in Fig. $1 \mathrm{~b}$ and Additional file 1: Fig. S4 demonstrated the stepwise loading of drugs in GPP and GmP. After the chelating $\mathrm{Cu}(\mathrm{II})$, GPPC displayed an obvious absorption peak at $603 \mathrm{~nm}$, indicating that $\mathrm{Cu}(\mathrm{II})$ had been successfully loaded into GPP. And the peak at $499 \mathrm{~nm}$ in GPPCT proved the encapsulation of TPZ and the formation of $\mathrm{Cu}(\mathrm{II}) / \mathrm{TPZ}$ complexes in nanoplatforms. The loading content (LC) and entrapment efficiency (EE) of TPZ (a)

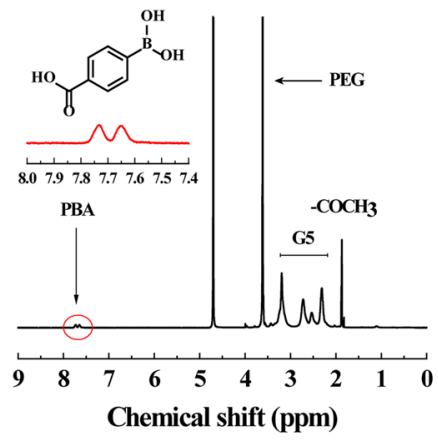

(d)

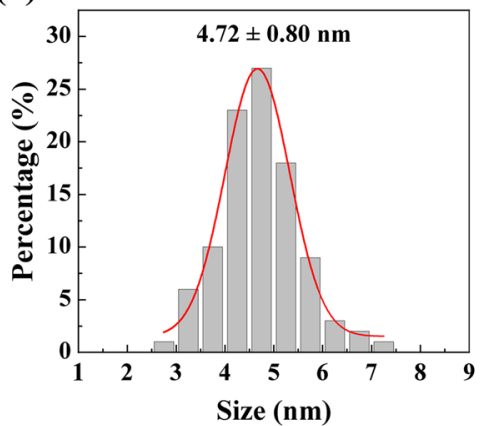

(b)

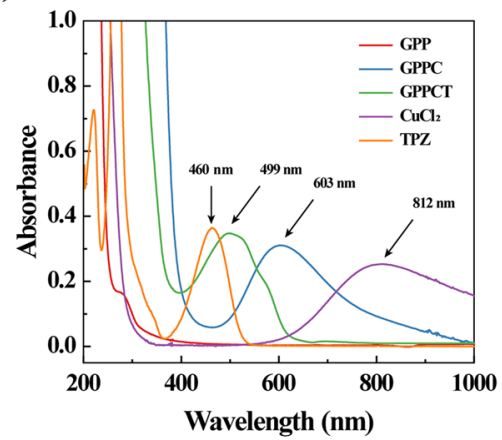

(e)

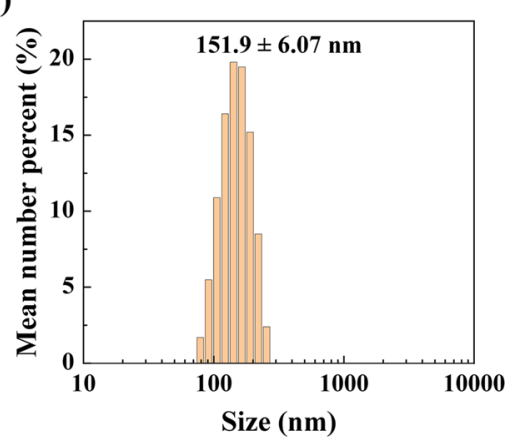

(c)

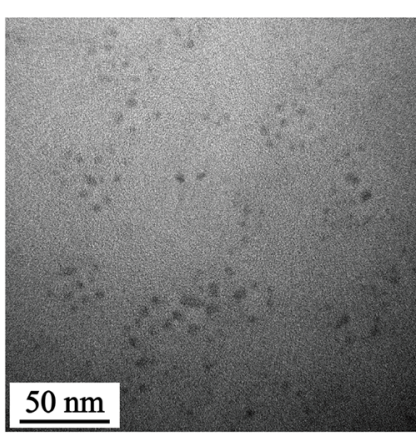

(f)

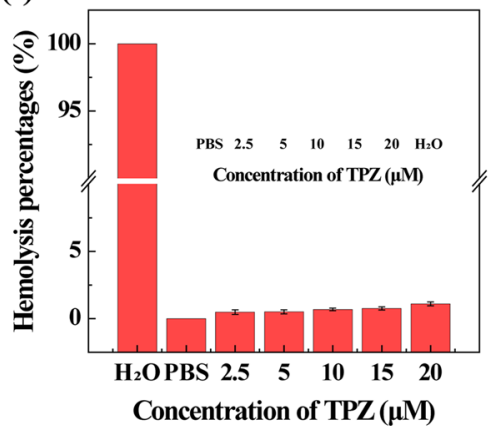

Fig. 1 a ${ }^{1} H$ NMR spectra of GPP. $\mathbf{b}$ UV-V is spectra of GPP, GPPC, GPPCT, CUCl 2 and TPZ. c TEM image and $\mathbf{d}$ size distribution histogram of GPPCT. e Hydrodynamic size distribution histogram of GPPCT. $\mathbf{f}$ Hematolysis rate and photographs of blood samples treated with PBS or GPPCT at different TPZ concentrations 
in GPPCT were calculated to be $2.26 \%$ and $65.03 \%$, and those for $\mathrm{GmPCT}$ were $2.38 \%$ and $66.67 \%$, respectively (Additional file 1: Table S1). In addition, the amount of $\mathrm{Cu}(\mathrm{II})$ in nanocomplexes was also measured by ICP-OES, and the average number of $\mathrm{Cu}(\mathrm{II})$ in each GPPCT and GmPCT was calculated to be 17.69 and 18.07 per dendrimer, respectively. Finally, the morphologies of GPPCT and $\mathrm{GmPCT}$ were evaluated by TEM in Fig. 1c and Additional file 1: Fig. S5a. Both nanoplatforms showed regular spherical structure with good mono-dispersity, and the mean size of $\mathrm{Cu}(\mathrm{II}) / \mathrm{TPZ}$ complexes in GPPCT and $\mathrm{GmPCT}$ were about $4.72 \pm 0.80 \mathrm{~nm}$ and $4.74 \pm 0.87 \mathrm{~nm}$ (Fig. 1d and Additional file 1: Fig. S5b). Both nanoplatforms had a similar mean hydrodynamic diameter of $150 \mathrm{~nm}$ (Fig. 1e, Additional file 1: Table S2 and Fig. S6), and kept good stability in water, PBS and DMEM media within seven days (Additional file 1: Fig. S7). As a result, targeted GPPCT and non-targeted GmPCT with similar size and drug content had been successfully synthesized for further comparison. To ensure the safe application of nanoplatforms in vivo, the hemolysis rate of GPPCT $([\mathrm{TPZ}]=2.5,5,10,15,20 \mu \mathrm{M})$ was evaluated in Fig. 1f. The red blood cells in the positive control group ruptured and the solution turned red, while the hemolysis rate of GPPCT nanoplatform was less than 5\%, indicating their good blood compatibility. Therefore, $\mathrm{Cu}(\mathrm{II})$ and TPZ loaded GPPCT nanoplatform with good colloidal stability and hemocompatibility were successfully synthesized for biomedical applications.

The drug release profiles of GPPCT at pH 7.4, 6.5 and 5.5 , which is to mimic the physiological environment, TME and weak acidic environment in lysosome respectively, were studied by ICP-OES for $\mathrm{Cu}$ and UV-Vis spectroscopy for TPZ. As shown in Fig. 2a, the amount of (a)

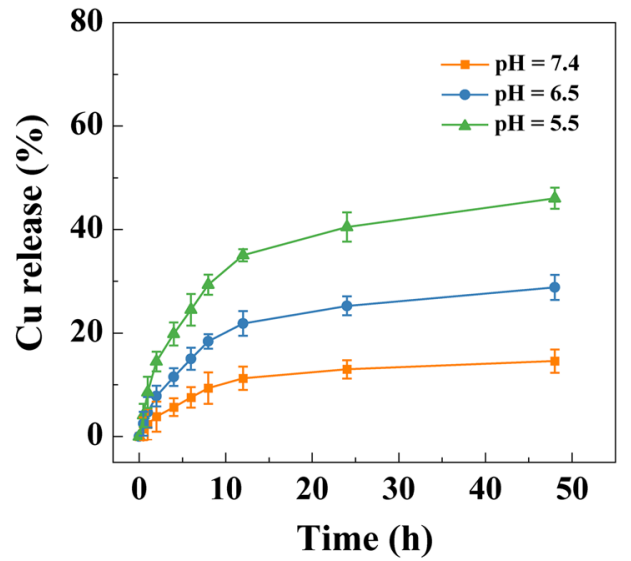

(c)

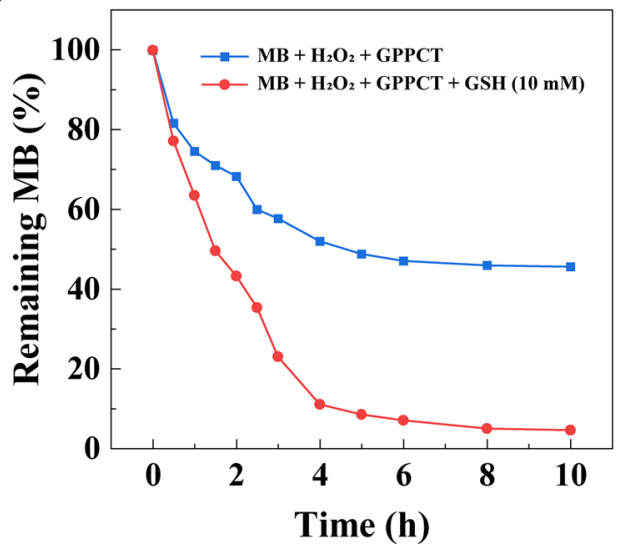

(b)

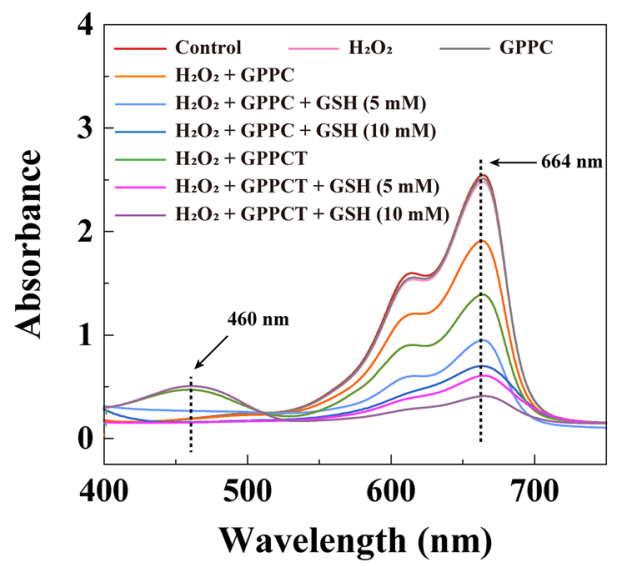

(d)

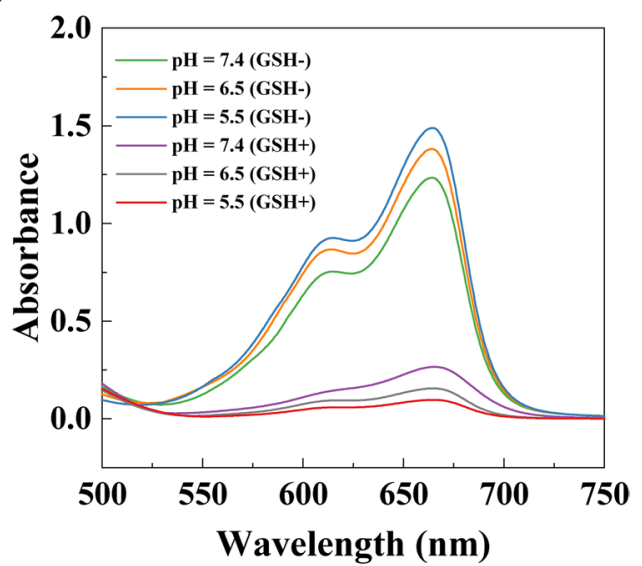

Fig. 2 a Accumulative release of $\mathrm{Cu}(I)$ from GPPCT in buffer solutions at different $\mathrm{pH}$ of 5.5, 6.5 and 7.4 ([GPPCT]=1 mg/mL). b UV-Vis spectra of MB solutions treated with $\mathrm{H}_{2} \mathrm{O}_{2}$ and GPPC or GPPCT with or without the presence of GSH for 4 h. c Degradation rate of $\mathrm{MB}$ treated with $\mathrm{H}_{2} \mathrm{O}_{2}$ and GPPCT with or without the presence of GSH within $10 \mathrm{~h}$. $\mathbf{d}$ UV-Vis spectra of MB treated with $\mathrm{H}_{2} \mathrm{O}_{2}$ and GPPCT with or without the presence of GSH at different $\mathrm{pH}$ of 5.5, 6.5 and 7.4. For $\mathbf{b}-\mathbf{d}$, the mixtures were kept under $37^{\circ} \mathrm{C}, \mathrm{MB}=10 \mu \mathrm{g} / \mathrm{mL},[\mathrm{GSH}]=5 \mathrm{mM}$ or $10 \mathrm{mM},\left[\mathrm{H}_{2} \mathrm{O}_{2}\right]=10 \mathrm{mM}$, $[\mathrm{TPZ}]=200 \mu \mathrm{M}$, and $[\mathrm{Cu}(\mathrm{II})]=616 \mu \mathrm{M})$ 
$\mathrm{Cu}$ released at $\mathrm{pH} 5.5$ within $48 \mathrm{~h}$ was about 3.15 times higher than that released at $\mathrm{pH} 7.4$ (46.05\% vs $14.56 \%)$. A similar $\mathrm{pH}$-sensitive release profile of TPZ could also be observed in Additional file 1: Fig. S8a, and a significantly higher amount of TPZ was released under weak acidic condition than in physiological situation. The $\mathrm{pH}$-sensitive release property of GPPCT should be attributed to the easier dissociation of $\mathrm{Cu}(\mathrm{II}) / \mathrm{TPZ}$ complex at a lower $\mathrm{pH}$ [15]. As a result, GPPCT nanoplatform may decrease the side effects by reducing drug release during body circulation, and release $\mathrm{Cu}(\mathrm{II})$ and TPZ quickly at weak acidic tumor sites for efficient CDT and chemotherapy.

Then the generation of ROS by GPPCT in different situations was determined by measuring the degradation of methylene blue (MB) with UV-Vis spectroscopy. As shown in Fig. 2b, the absorption at $664 \mathrm{~nm}$ did not change after mixing with only $\mathrm{H}_{2} \mathrm{O}_{2}$ or GPPC for $4 \mathrm{~h}$, indicating the good stability of $\mathrm{MB}$ under these conditions. With the addition of $\mathrm{H}_{2} \mathrm{O}_{2}$ and GPPC, the absorption intensity of $\mathrm{MB}$ decreased $26.44 \%$. This proved that $\mathrm{Cu}$ (II) in GPPC could react with $\mathrm{H}_{2} \mathrm{O}_{2}$ to generate $\cdot \mathrm{OH}$ and induce the degradation of $\mathrm{MB}$. More interestingly, when GSH was added, the degradation rate was accelerated significantly with the increase of GSH concentration. The absorption intensity decreased almost three folds at $10 \mathrm{mM} \mathrm{GSH}$, indicating that about $76.72 \%$ of MB had been degraded. This should be mainly due to that $\mathrm{GSH}$ may reduce $\mathrm{Cu}(\mathrm{II})$ to $\mathrm{Cu}(\mathrm{I})$, which has a higher Fenton reaction efficiency. It is worth noting that GPPCT may further enhance the MB degradation to a level of $88.79 \%$ with the aid of TPZ, illustrating their capability in massive $\cdot \mathrm{OH}$ production. To verify the function of TPZ, $\mathrm{UV}-\mathrm{Vis}$ spectra of $\mathrm{MB}$ in the presence of TPZ were monitored in Additional file 1: Fig. S8b. It is clearly that TPZ can degrade $\mathrm{MB}$ efficiently with/without the existence of $\mathrm{H}_{2} \mathrm{O}_{2}$ and the degradation became more thorough at a high GSH concentration. This result indicated that in the presence of excessive GSH in TME, TPZ may further increase the inhibition effect of GPPCT nanoplatforms at tumor sites. Furthermore, the degradation process of $\mathrm{MB}$ over time in Fig. 2c suggested that $\mathrm{OH}$ groups could be produced continuously by GPPCT nanoplatform in the existence of GSH, implying their long-term and efficient therapeutic effect on malignant tumors. Finally, ROS generation in different $\mathrm{pH}$ environments $(5.5,6.5$, and 7.4) was evaluated in Fig. 2d. Clearly, the degradation rate of $\mathrm{MB}$ enhanced with the decrease of $\mathrm{pH}$, and about $92.12 \%$ of $\mathrm{MB}$ were degraded at $\mathrm{pH} 5.5$ in the presence of $\mathrm{GSH}$, as a result of considerable $\cdot \mathrm{OH}$ generation by GPPCT in TME. Therefore, the $\mathrm{pH}$ responsive drug release property and high toxic radical producing efficiency make GPPCT an excellent nanoplatform for synergistic CDT and chemotherapy.

\section{Cellular uptake and cytotoxicity of GPPCT}

4T1 breast cancer cell lines overexpressing sialic acid residues were chosen as model cells in this study. To simulate hypoxia situation, hypoxia model of 4T1 cells were set by incubating with $\mathrm{CoCl}_{2} \cdot 6 \mathrm{H}_{2} \mathrm{O}(100 \mu \mathrm{M})$ for $24 \mathrm{~h}$ according to previous studies [33] (Additional file 1: Fig. S9a), and the expression of hypoxia inducible factor HIF- $1 \alpha$ was verified by Western Blot in Additional file 1: Fig. S9b and c. Compared with normoxic 4T1 cells, the HIF-1 $\alpha$ expression of hypoxia 4T1 cells enhanced significantly, indicating the successful construction of hypoxia cell model. Therefore, mouse fibroblast L929 cells, normoxic and hypoxic 4T1 cells were applied firstly to assess the biocompatibility of GPP nanocarriers by CCK-8 method. As shown in Additional file 1: Fig. S10, the viability of different cells was higher than $80 \%$ after incubation with GPP in the studied concentration range, suggesting the good biocompatibility of GPP as a nanocarrier.

To evaluate the targeted delivery and cellular uptake of GPPCT, laser confocal microscope (Fig. 3a) and flow cytometry (Fig. 3b) were used to examine the red fluorescence of TPZ after incubation with normoxic and hypoxic $4 \mathrm{~T} 1$ cells for $6 \mathrm{~h}$. It could be clearly seen that red fluorescence signals were concentrated well in cytoplasm of both normoxic and hypoxic 4T1 cells after incubation with nanoplatforms, and GPPCT group showed much brighter signals in comparison with GmPCT group. This demonstrated that GPPCT could be selectively uptaken by $4 \mathrm{~T} 1$ cells through the specific recognition between PBA on GPPCT and the overexpressed sialic acid on 4T1 cell membranes. The targeting property of GPPCT was further proved by the result of flow cytometry. As shown in Fig. 3b, the fluorescence intensity of GPPCT group was significantly higher than GmPCT group at all TPZ concentrations. Moreover, the fluorescence intensity of GPPCT group in hypoxia 4T1 cells was much stronger than that of normoxic 4T1 cells, and more red spots in the nucleus could be observed in Fig. 3a. These results further proved that TPZ can be activated under hypoxic conditions and enter the nucleus more effectively, which may exert drug activity more efficiently to hypoxic tumors [34]. In addition, the cellular $\mathrm{Cu}$ content after incubation with GPPCT and GmPCT nanoplatforms was measured by ICP-OES in Fig. 3c in order to further verify their targeting property. With the increase of nanoplatforms concentration, the cellular $\mathrm{Cu}$ concentration increased significantly, indicating that both nanoplatforms could be endocytosed into cells due to their suitable nano-size. More importantly, GPPCT nanoplatforms displayed a significantly higher $\mathrm{Cu}$ concentration than non-targeted GmPCT group $(\mathrm{p}<0.001)$. The selective binding of PBA with sialic acid residues overexpressed on $4 \mathrm{~T} 1$ cells is expected to be the cause of this difference 


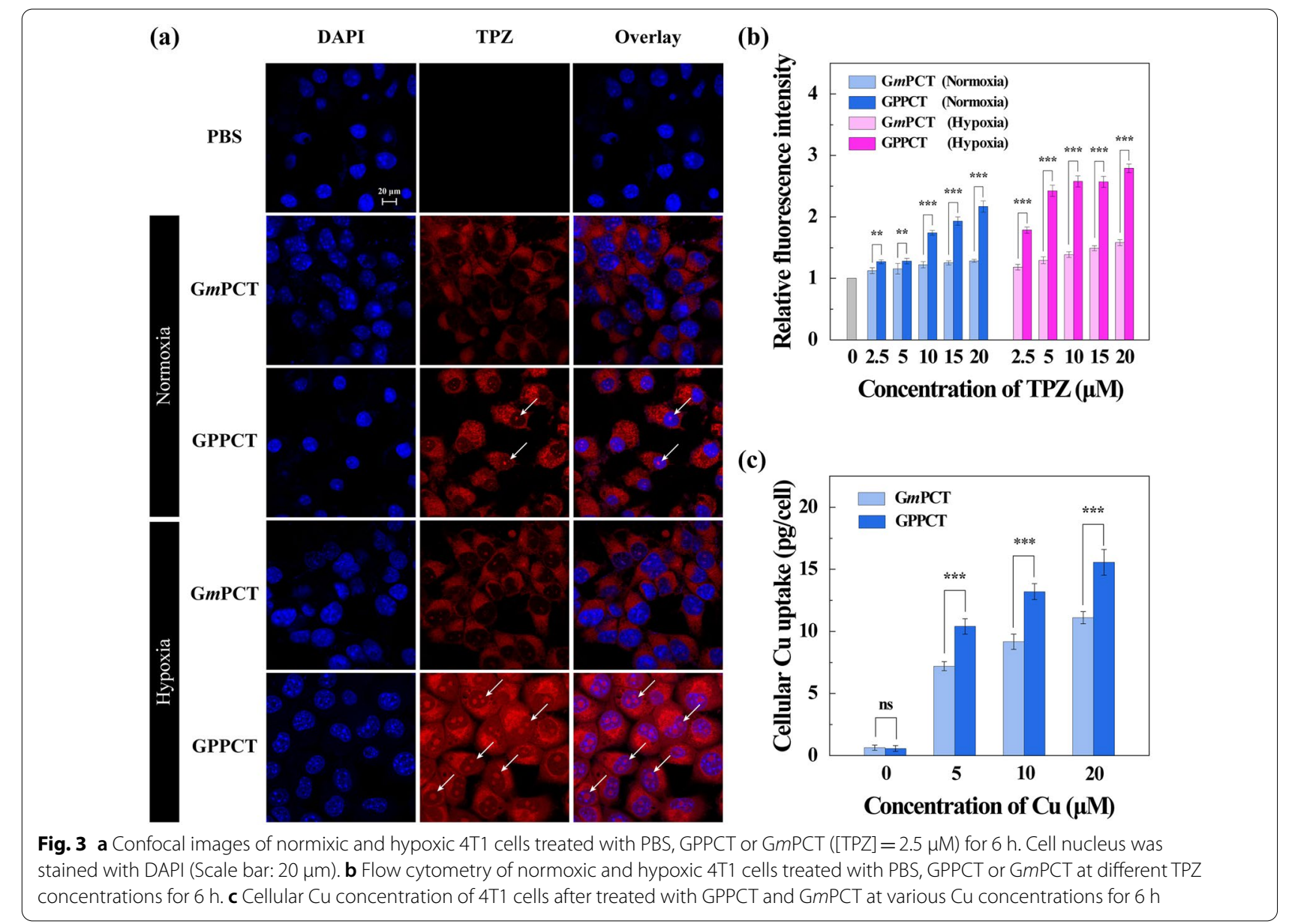

(b)

in cellular uptake. In conclusion, targeted GPPCT nanoplatform can be specifically uptaken by $4 \mathrm{~T} 1$ cells overexpressing sialic acid residues, and released TPZ could be more efficiently activated in hypoxic tumor cells, which will further enhance the therapeutic effect of GPPCT nanoplatform on hypoxic tumors.

Subsequently, the viabilities of L929, normoxic and hypoxic 4T1cells were evaluated by incubating with TPZ, GPPC, GPPCT and GmPCT at different TPZ concentrations $(0,2.5,5,10,15,20,25 \mu \mathrm{M})$ for $24 \mathrm{~h}$ (Fig. 4 and Additional file 1: Fig. S11). For free TPZ (Fig. 4a), the viability of all three kinds of cells decreased with the increase of drug concentration, and hypoxic 4T1 cells displayed a much lower viability than normoxic 4T1 cells and L929 cells at TPZ concentration over $10 \mu \mathrm{M}$. This difference should be attributed to the responsive formation of highly toxic TPZ radicals within hypoxic cells, which will in turn induce single-strand/double-strand DNA breakage through the mediation of topoisomerase II and chromosomal destruction [35-37]. In Fig. 4b, GPPC nanoplatforms displayed obvious toxicity to both normoxic and hypoxic 4T1 cells, but almost no inhibition to mouse fibroblast L929 cells was observed. This result suggested that $\mathrm{Cu}(\mathrm{II})$ complexed in GPPC could exert inhibitory effect specifically on tumor cells with high endogenous $\mathrm{H}_{2} \mathrm{O}_{2}$ level, and do less harm to normal cells. In Fig. 4c, the inhibitory effect of GPPCT between different cell lines were systemically compared. L929 cells displayed the highest cell viability, while the viability of both hypoxic and normoxic 4T1 cells decreased rapidly with the increase of drug concentration, indicating that GPPCT nanoplatforms could display the most prominent inhibition effect specific to tumor cells. Hypoxic 4T1 cells displayed a significantly poorer viability than normoxic $4 \mathrm{~T} 1$ cells at a low GPPCT concentration, possibly due to that hypoxic-sensitive TPZ could be converted to toxic radicals responsively within hypoxic cells and enhance the therapeutic effect. Figure $4 d$ evaluated the inhibition effect of TPZ, GPPC, GmPCT, and GPPCT on hypoxic $4 \mathrm{~T} 1$ cells. It is clearly that GPPCT displayed a significantly lower viability than TPZ or GPPC group alone at the studied concentrations $(\mathrm{p}<0.001)$, verifying their synergistic effect of hypoxia-enhanced chemotherapy and CDT on hypoxic tumor cells. In addition, the cell viability 

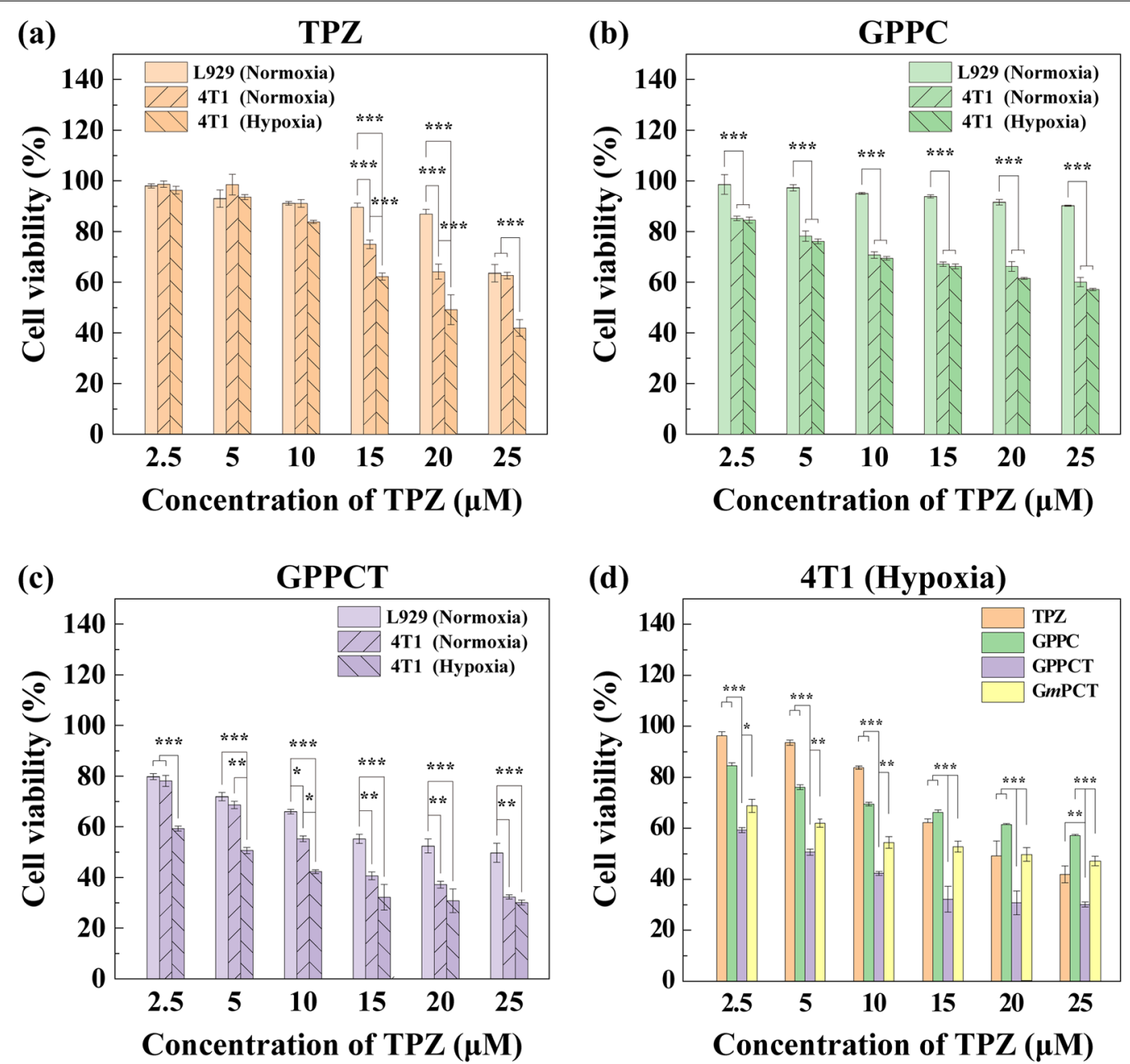

Fig. 4 Cell viability of L929 (normoxia) cells and 4T1 (hypoxia and normoxia) cells after incubation with a TPZ, b GPPC and $\mathbf{c}$ GPPCT for $24 \mathrm{~h}$ detected by CCK-8 assay. $\mathbf{d}$ Cell viability of hypoxic 4T1 cells after incubation with free TPZ, GPPC, GPPCT and GmPCT for $24 \mathrm{~h}$

of GPPCT group was significantly lower than GmPCT group, suggesting that GPPCT nanoplatform could target tumor cells overexpressing sialic acid residues and efficiently induce cell apoptosis. In contrast, the inhibition effect of GPPCT and GmPCT on normoxic 4T1 cells did not display significant difference at a low drug concentration (Additional file 1: Fig. S11) due to the poor activity and toxicity of $\mathrm{TPZ}$ at normoxic situation. The $\mathrm{IC}_{50}$ values of GPPCT to different cells were calculated in Additional file 1: Table S3. The $\mathrm{IC}_{50}$ value of GPPCT on L929 cells was as high as $24.05 \mu \mathrm{M}$, which was 2.1 times higher than normoxic $4 \mathrm{~T} 1$ cells $(11.70 \mu \mathrm{M})$, and 4.8 times higher than hypoxic $4 \mathrm{~T} 1$ cells $(5.03 \mu \mathrm{M})$. This result further demonstrated that GPPCT could specifically inhibit tumor cells, and exhibit an enhanced therapeutic effect on hypoxic cells which are less susceptible to general chemotherapy. The safety indexes of hypoxic and normoxic 4T1 cells were 4.78 and 2.06 , respectively, verifying again the good safety of the nanoplatforms. In conclusion, GPPCT can be used as an ideal targeted nanoplatform for the synergistic hypoxia-responsive chemotherapy and CDT of cancer cells overexpressing sialic acid residues.

\section{Determination of ROS and GSH/GSSG levels in cells}

In order to better illustrate the antitumor mechanism of GPPCT nanoplatforms at cellular level, 2',7'-dichlorofluorescin diacetate (DCFH-DA) was used as a fluorescent indicator to detect reactive oxide species formed in cells [38, 39]. In Fig. 5a, 4T1 cells incubated with GPPC showed obvious green fluorescence signals in comparison with PBS control. This result indicated that toxic $\cdot \mathrm{OH}$ were generated by Fenton-like reaction between $\mathrm{Cu}$ (II) released from GPPC nanoplatform and endogenous $\mathrm{H}_{2} \mathrm{O}_{2}$, inducing the formation of $2^{\prime}, 7^{\prime}$-dichlorofluorescein (DCF) with fluorescence in cells. The green fluorescence in cells treated with GPPCT under normoxic or hypoxic 


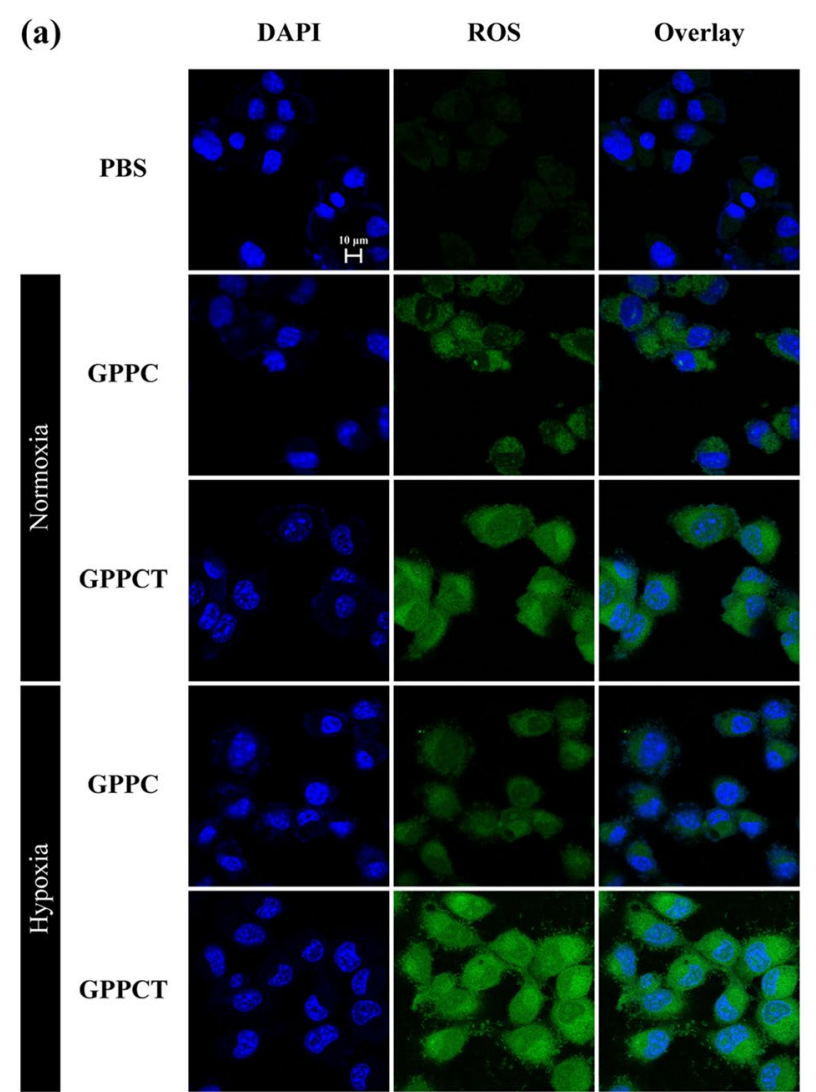

(b)

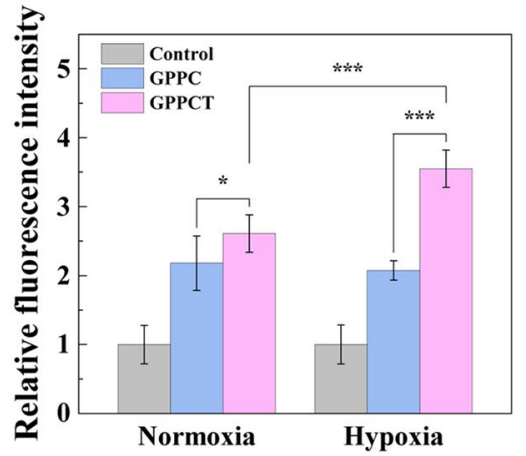

(c)

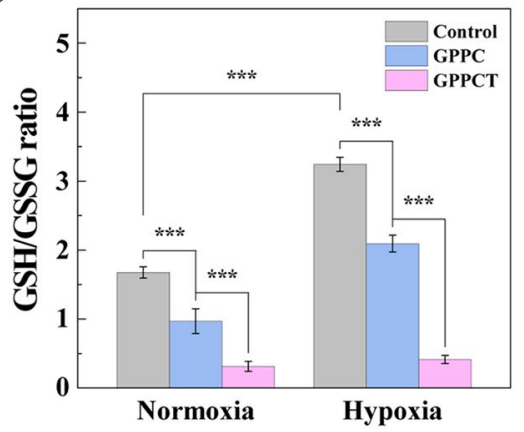

Fig. 5 a Confocal images of normixic and hypoxic 4T1 cells treated with PBS, GPPC or GPPCT for $6 \mathrm{~h}$. Cell nucleus was stained with DAPI (Scale bar: $10 \mu \mathrm{m})$. b Intracellular ROS generation and c GSH/GSSG ratio in normoxic and hypoxic 4T1 cells treated with PBS, GPPC or GPPCT for $6 \mathrm{~h}$. For $\mathbf{a}-\mathbf{c}$, $[\mathrm{TPZ}]=2.50 \mu \mathrm{M}$, equivalent to $[\mathrm{Cu}(\mathrm{II})]=7.69 \mu \mathrm{M}$

conditions was much brighter than that of GPPC group, suggesting that TPZ can produce additional reactive radicals, in consistent with the result in Fig. $2 \mathrm{~b}$ and Additional file 1: Fig. S8b. And the hypoxic 4T1 cells showed much stronger fluorescence signal than normoxic 4T1 cells due to the easier activation of TPZ under hypoxia condition, which would lead to the formation of toxic $\mathrm{BTZ}$ radical and $\cdot \mathrm{OH}$. Figure $5 \mathrm{~b}$ showed the quantitative analyzation of fluorescence intensity by flow cytometry. After treated with nanoplatform, 4T1 cells displayed an enhanced fluorescence intensity, and GPPCT caused a much stronger fluorescence signal than GPPC in both hypoxic $(\mathrm{p}<0.001)$ and normoxic 4T1 cells $(\mathrm{p}<0.05)$ due to the encapsulation of TPZ. More importantly, the fluorescence intensity in hypoxic 4T1 cells of GPPCT group was much higher than that in normoxic $4 \mathrm{~T} 1$ cells, while no significant difference was observed in GPPC treated 4T1 cells. This further demonstrated that TPZ can produce more reactive radicals under hypoxia conditions, which may boost the therapeutic effect of GPPCT on hypoxia tumors. Moreover, the GSH content in $4 \mathrm{~T} 1$ cells under normoxic and hypoxic conditions was measured to further verify the function of GSH in tumor treatment. As shown in Fig. 5c, GSH content in hypoxic 4T1 cells was significantly higher than normoxic ones, which would facilitate the reduction of $\mathrm{Cu}(\mathrm{II})$ to $\mathrm{Cu}(\mathrm{I})$ and promote the Fenton reaction efficiency for CDT. After incubation with GPPC, the GSH content in normoxic and hypoxic cells decreased significantly $(\mathrm{p}<0.001)$ due to the consumption of $\mathrm{GSH}$ for $\mathrm{Cu}(\mathrm{II}) / \mathrm{Cu}(\mathrm{I})$ reduction. In comparison with GPPC, the GSH/GSSH ratio of normoxic and hypoxic cells decreased significantly after GPPCT treatment $(\mathrm{p}<0.001)$, suggesting that GSH played an important role in the activation of TPZ in hypoxic cells. As a result, the excessive GSH in tumor cells could be depleted by the reduction of $\mathrm{Cu}(\mathrm{II})$ to $\mathrm{Cu}(\mathrm{I})$ and converting TPZ to active radicals, which may in turn break the redox homeostasis in tumor cells, and improve the CDT efficacy. In conclusion, the GPPCT nanoplatform may efficiently produce toxic ROS, reduce the GSH level in cancer cells, and successfully enhance the therapeutic effect to tumors. 


\section{In vivo antitumor effect of GPPCT}

To verify the therapeutic effect of GPPCT in vivo, $\mathrm{BALB} / \mathrm{c}$ nude mice transplanted with $4 \mathrm{~T} 1$ tumors were randomly divided into 6 groups (PBS, GPP, GPPC, CPPCT, GmPCT, and TPZ, $\mathrm{n}=5$ ) when the tumor size reached about $200 \mathrm{~mm}^{3}$. Intravenous administration was planned on day 1, 4, 7, 10, 13, and 16 (Fig. 6a), and body weight (Fig. 6b) and relative tumor volume (Fig. 6c and Additional file 1: Fig. S12) were measured every 3 days. There were no mice dead in all groups during the treatment, and the body weight showed no significant decrease as depicted in Fig. 6b, indicating that nanoplatforms had no obvious toxic and side effect. As shown in Fig. $6 \mathrm{c}$, the relative tumor volume of PBS and GPP groups increased by $14-15$ times, indicating that pure nanocarrier GPP had no inhibition effect on tumors. Although the relative tumor size of free TPZ group displayed a lower tumor growth rate as 10.24 times, the therapeutic effect is still quite poor possibly due to its fast metabolism in blood circulation and the low uptake in tumor cells. In contrast, GPPC group showed a significantly better inhibition effect with a tumor volume increase of only 6.27 times $(\mathrm{p}<0.001)$. This should be attributed to that targeted GPPC nanoplatforms could effectively generate toxic $\cdot \mathrm{OH}$ at tumor sites for $\mathrm{CDT}$. More encouragingly, the relative tumor size of GPPCT group was only about $51 \%$ of $\mathrm{GmPCT}$ group, $22 \%$ of TPZ group and $37 \%$ of GPPC group $(p<0.001)$. The magnificent inhibition effect of GPPCT could be mainly attributed to the following two factors: (1) the specific accumulation and efficient uptake of drugs at tumors, and (2) the synergistic therapeutic effect of CDT by $\mathrm{Cu}(\mathrm{II})$ and hypoxia-enhanced chemotherapy by TPZ. After all mice were sacrificed on day 21, tumor tissues were extracted and weighted as shown in Fig. 6d. Among different groups, the tumor weight of GPPCT group was the lowest. All these results clearly demonstrated the outstanding in vivo antitumor effect of targeted GPPCT nanoplatforms could effectively inhibit the growth of sialic acid overexpressed 4T1 tumors as a result of the synergistic therapeutic effect of hypoxia-enhanced chemotherapy and CDT. (a)

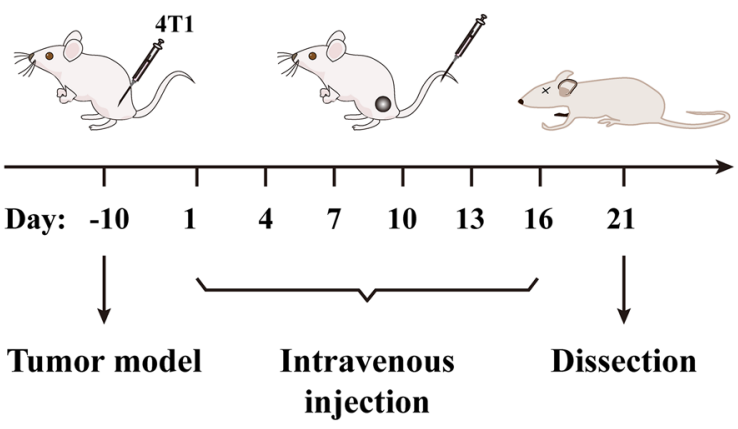

(c)

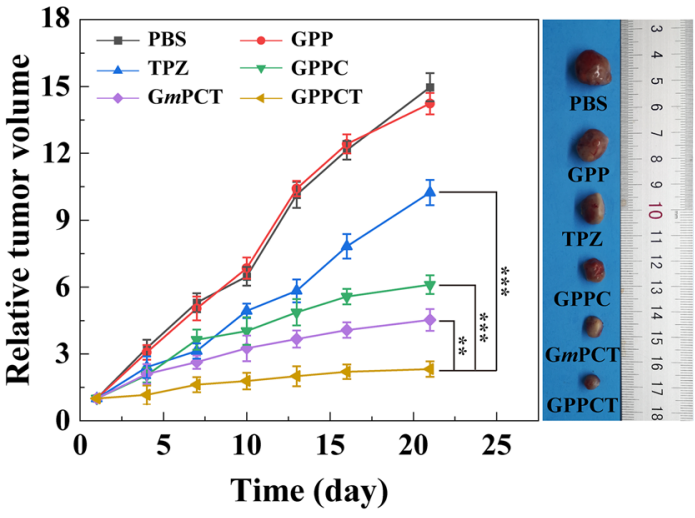

(b)

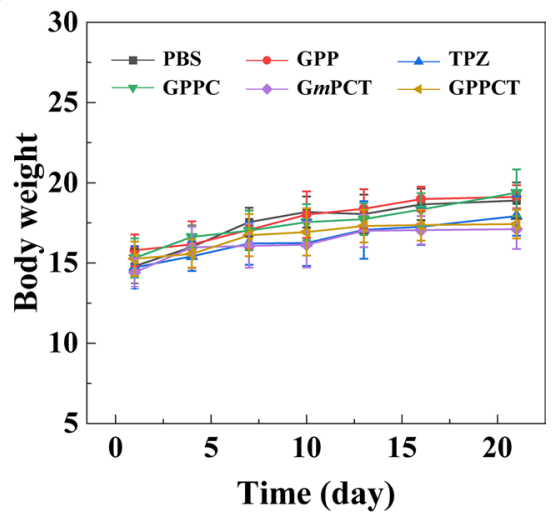

(d)

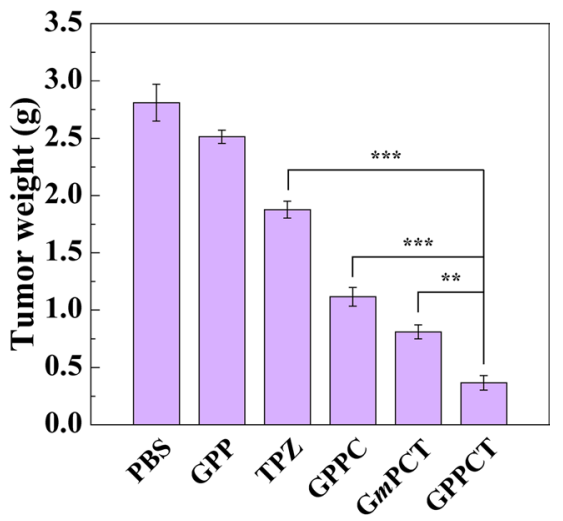

Fig. 6 a Treatment schedule of the in vivo antitumor experiment ([TPZ] $=2 \mathrm{mg} / \mathrm{kg}, 100 \mu \mathrm{L})$. b Body weight, $\mathbf{c}$ relative tumor volume, representative tumor photographs and $\mathbf{d}$ tumor weight of mice after different treatments $(n=5)$ 
To further illustrate the therapeutic mechanism in vivo, H\&E, TUNEL, Ki-67, HIF-1 $\alpha$, and DHE staining were performed on tumor sections as shown in Fig. 7a. In H\&E staining image, the reduced blue signal indicated that most tumor tissues in GPPCT group were necrotic. In the TUNEL staining image, an enhancing green fluorescence signal was observed from TPZ, GPPC, GmPCT to GPPCT group, suggesting that more DNA fragments were formed by GPPCT treatment. According to Additional file 1: Fig. S13a, the apoptosis rate of GPPCT group was calculated to be $95.90 \%$, which was significantly higher than that of $\mathrm{GmPCT}(78.48 \%)$, GPPC (48.92\%), and free TPZ (30.91\%) group $(\mathrm{p}<0.001)$. In the Ki-67 antibody staining assay, a similar ascending sequential order of cell proliferation was observed, and GPPCT displayed the lowest Ki-67 expression level as 8.37\% (Additional file 1: Fig. S13b). Since TPZ could be metabolized in hypoxic cells to produce DNA-damaging radicals and kill hypoxic cells selectively, the expression of HIF-1 $\alpha$ in tumors was detected by hypoxyprobe immunofluorescence assay to assess the ratio of hypoxic cells

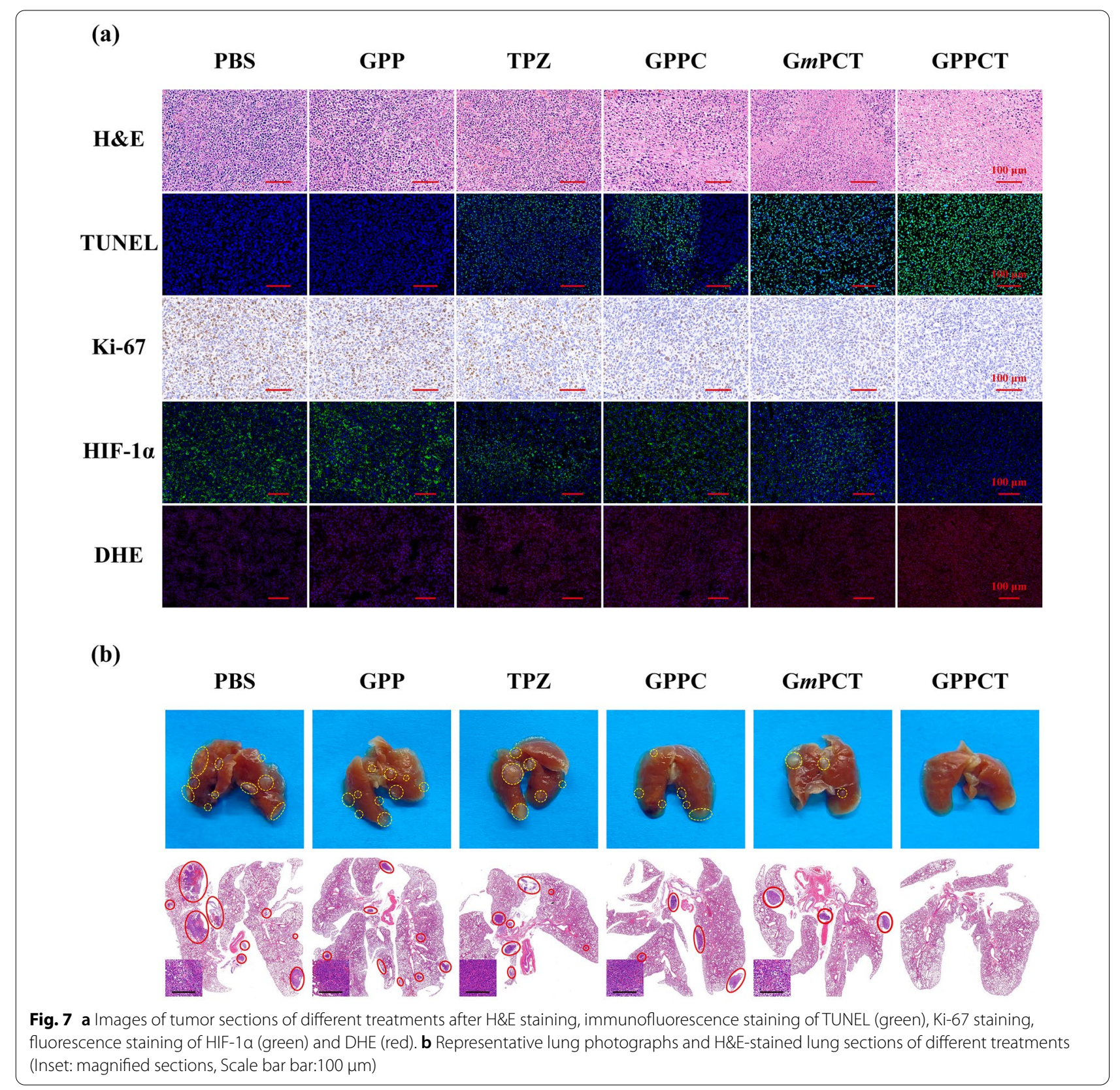


in tumor region in Fig. 7a. Strong green fluorescence signal of HIF- $1 \alpha$ could be observed in the tumor section of PBS group, which indicated that large number of hypoxic cells existed in solid tumor in vivo by the rapid growth of tumor. In contrast, the tumor section after GPPCT treatment displayed almost no green fluorescence signal. As calculated in Additional file 1: Fig. S13c, the HIF-1 $\alpha$ expression level of GPPCT group was only $5.52 \%$ of PBS group, while that of TPZ, GPPC, and GmPCT groups was $37.90 \%, 49.25 \%$, and $31.19 \%$, respectively. This result again demonstrated that GPPCT could effectively inhibit hypoxic tumors in vivo by specific targeting and combination therapy. In addition, local ROS production in tumor region was also detected by using dihydroethidium (DHE) as a fluorescence probe in Fig. 7a. For GPPCT, GmPCT, GPPC, and free TPZ groups, the red fluorescence signals appeared in tumor section resulting from the generation of ROS at tumor sites in vivo. The average red fluorescence intensity of GPPCT group was significantly higher than that of free TPZ, GPPC, and GmPCT groups $(\mathrm{p}<0.001)$ as shown in Additional file 1: Fig. S13d. This result verified that GPPCT nanoplatforms could produce toxic ROS more efficiently at tumor than other groups, which should be mainly due to three reasons. Firstly, GPPCT could specifically accumulate at tumor sites and be efficiently uptaken by tumor cells via the binding between PBA on GPPCT and sialic acid residues overexpressed on $4 \mathrm{~T} 1$ cells for the targeted delivery of $\mathrm{Cu}(\mathrm{II})$ and TPZ. Secondly, the excessive intracellular GSH would be depleted by reducing $\mathrm{Cu}$ (II) to $\mathrm{Cu}(\mathrm{I})$ and activating TPZ in hypoxic tumor cells, which suppresses the cellular antioxidative system for ROS scavenging. Thirdly, abundant $\mathrm{OH}$ radicals would be produced via the Fenton-like reaction between $\mathrm{Cu}(\mathrm{I})$ and endogenous $\mathrm{H}_{2} \mathrm{O}_{2}$, and effectively inhibit solid tumor with the hypoxiaactivated TPZ radicals in a synergistic manner.

Considering the highly invasive and aggressive nature of breast cancer 4T1 model, the lung tissues in different groups were collected and $\mathrm{H} \& \mathrm{E}$ stained to assess tumor metastasis to distant organs (Fig. 7b). A large number of metastatic sites could be clearly seen in the lungs of PBS and GPP group, while the treatment groups of TPZ and GPPC displayed a much lower number of pulmonary metastatic sites. Notably, compared with GmPCT group, GPPCT group showed a relatively intact lung structure with almost no metastasis, demonstrating the tumor invasion could be effectively inhibited by GPPCT. Therefore, GPPCT nanoplatforms could be an effective antitumor strategy to inhibit the growth and metastasis of tumors by the combination of hypoxia-enhanced chemotherapy and CDT.

\section{In vivo biodistribution and biosafety of GPPCT}

To understand the biological distribution of GPPCT and $\mathrm{G} m \mathrm{PCT}$ in vivo, the contents of copper in heart, liver, spleen, lung, kidney and tumors at different time intervals were determined by ICP-OES (Fig. $8 \mathrm{a}-\mathrm{c}$ ). For both targeted and non-targeted nanoplatforms, the $\mathrm{Cu}$ content in liver, lung and tumor increased significantly after intravenous injection, and peaked at $2 \mathrm{~h}$. Then the $\mathrm{Cu}$ concentration in all major organs decreased to normal level after $72 \mathrm{~h}$ by metabolization, implying that the injected nanoplatforms were almost completely cleared from the body within 3 days. It is worth noting that the $\mathrm{Cu}$ content in tumor tissue of targeted GPPCT group was significantly higher than GmPCT group within $8 \mathrm{~h}$ after injection $(\mathrm{p}<0.01)$. This result indicated that GPPCT nanoplatforms could more effectively accumulate at tumor sites by the specific recognition of PBA to sialic acid resides overexpressed on $4 \mathrm{~T} 1$ cancer cells, and be safely excreted from the body.

The biotoxicity of nanoplatforms to major organs after different treatments was evaluated by $\mathrm{H} \& \mathrm{E}$ staining assays shown in Fig. 8d. No apparent inflammation or cell necrosis and apoptosis were observed in heart, liver, spleen, and kidney, indicating the good biocompatibility of GPPCT nanoplatforms. Finally, the routine blood and blood biochemical analysis were performed after GPPCT treatment [38]. No obvious abnormality was observed in Additional file 1: Fig. S14, suggesting the good compatibility of GPPCT, and the proper liver and kidney function after GPPCT treatment. In conclusion, the biodistribution study of GPPCT nanoplatforms further confirmed the targeting effect to tumor overexpressing sialic acid residues, and they can be metabolized without significant damage to normal organs, which is of great importance for in vivo biomedical applications.

\section{Conclusions}

In summary, a TME-responsive and targeted GPPCT nanoplatform was synthesized for the combination of hypoxia-sensitive chemotherapy and CDT for tumors overexpressing sialic acid residues. The GPPCT nanoplatform has good colloidal stability, high drug loading capacity and efficiency, and $\mathrm{pH}$-sensitive drug release property. In vitro experiments demonstrated that GPPCT could be specifically uptaken by cancer cells overexpressing sialic acid residues, effectively generate ROS within cells and deplete GSH, and significantly kill hypoxic tumor cells because of the activation of TPZ under a hypoxic situation. In vivo results showed that GPPCT nanoplatforms could be specifically accumulated at tumor sites after long circulation, and effectively inhibit the growth and metastasis of 4T1 breast tumor by 
(a)

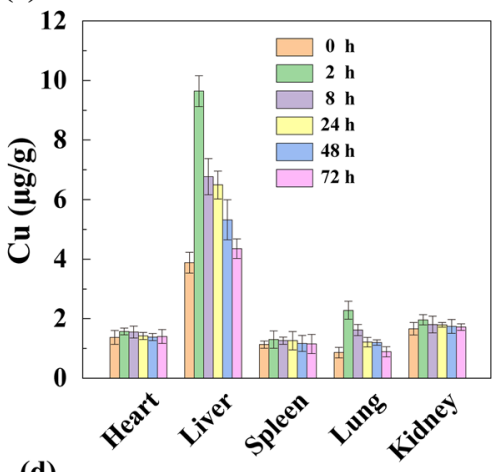

(b)

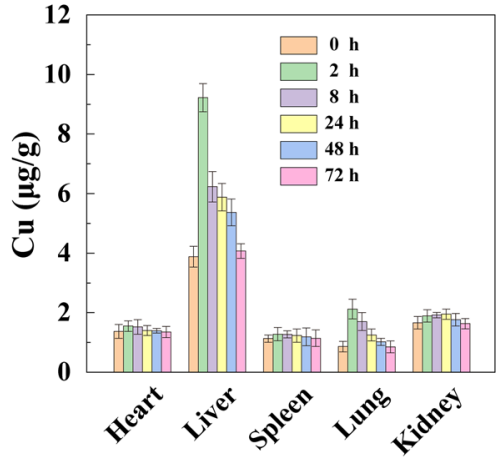

(c)

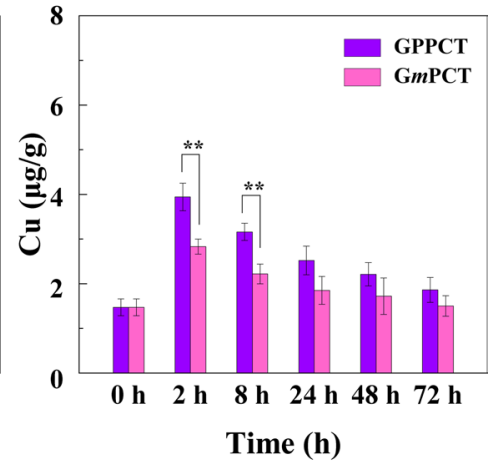

(d)

PBS

GPP

TPZ

GPPC

GmPCT

GPPCT

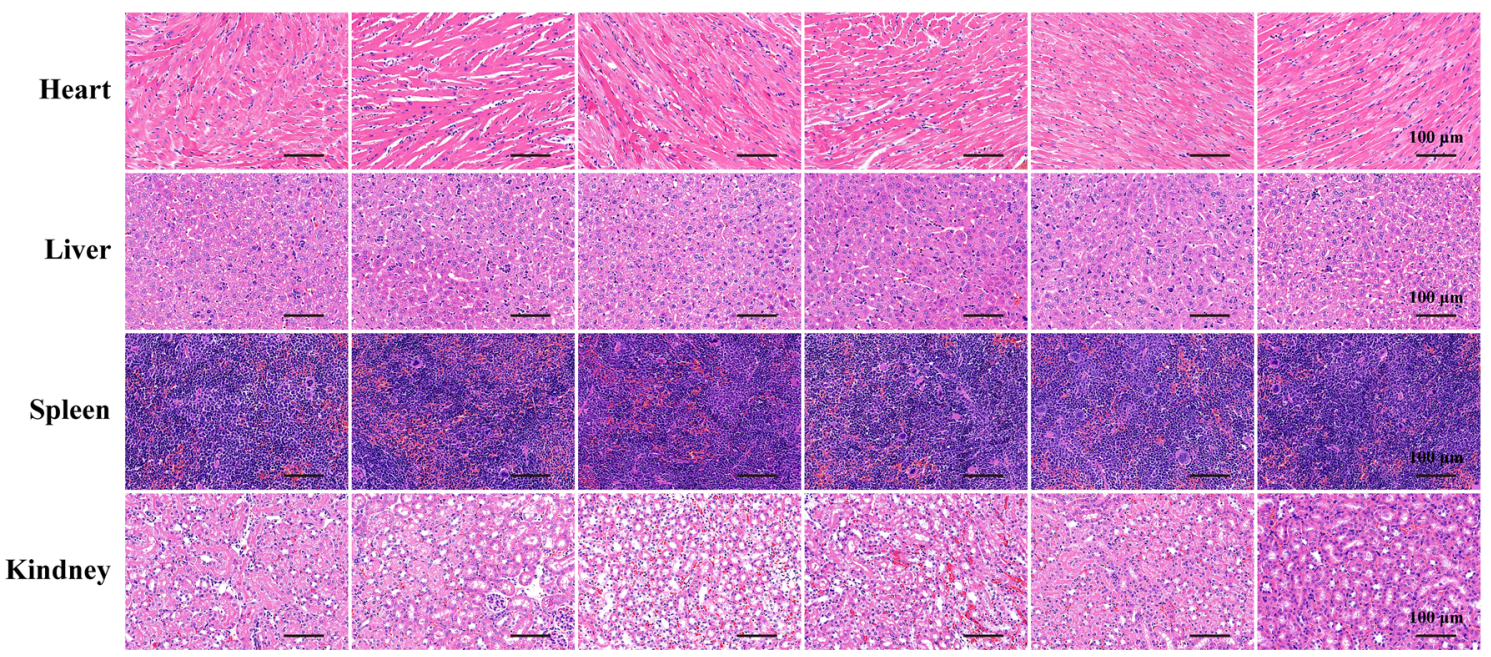

Fig. 8 Biodistribution of $\mathrm{Cu}$ in major organs of mice post-intravenous injection of $\mathbf{a}$ GPPCT and $\mathbf{b}$ GMPCT at different time points. $\mathbf{c} C u$ concentration in tumors post-intravenous injection of GPPCT and GmPCT. For a-c, $[\mathrm{Cu}(\mathrm{II})]=6.9 \mathrm{mM}$, equivalent to $[\mathrm{TPZ}]=2 \mathrm{mg} / \mathrm{kg}$ for each mouse. $\mathbf{d}$ H\&E-stained slices of major organs of $4 \mathrm{~T} 1$ tumor-bearing mice after different treatments

the combination of CDT and chemotherapy. Moreover, they can be metabolized with no significant systemic toxicity. Therefore, in this study, the targeted GPPCT nanoplatform with synergistic CDT and hypoxia-responsive chemotherapy provides an efficient and safe strategy for therapy of tumors and tumor metastasis.

\section{Materials and methods}

Please see Additional file 1.

\section{Abbreviations}

TME: Tumor microenvironment; $\mathrm{H}_{2} \mathrm{O}_{2}$ : Hydrogen peroxide; GSH: Glutathione; CDT: Chemodynamic therapy; ROS: Reactive oxygen species; $\cdot \mathrm{OH}$ : Hydroxyl radicals; pH: Potential of hydrogen; NPs: Nanoparticles; TPZ: Tirapazamine; BTZ: Benzotriazinyl; PEG: Polyethylene glycol; PBA: Phenylboronic acid; PAMAM: Poly(amidoamine); GPPCT: G5.NHAc-PEG-PBA@Cu(II)/TPZ; GmPCT: G5.NHAcmPEG@Cu(II)/TPZ; 4-CPBA: 4-Hydroxyphenylboronic acid; GPP: G5.NHAc-PEGPBA; GmP: G5.NHAc-mPEG; LC: Loading content; GPPC: G5.NHAc-PEG-PBA@ Cu(II); GmPC: G5.NHAc-mPEG@Cu(II); EE: Entrapment efficiency; ICP-OES: Inductively coupled plasma-optical emission spectroscopy; MB: Methylene blue; CCK-8: Cell counting kit-8; DCFH-DA: 2',7'-Dichlorofluorescin diacetate;
DCF: 2,7'-Dichlorofluorescein; PBS: Phosphate buffer saline; H\&E: Hematoxylin-eosin staining; TUNEL: TdT-mediated dUTP Nick-End Labeling; HIF-1a: Hypoxia-inducible factor-1a; DHE: Dihydroethidium; EDC: 1-Ethyl-3-(3-dimethylaminopropyl)carbodiimide; NHS: N-Hydroxysuccinimide; MWCO: Molecular weight cut-off; DMSO: Dimethyl sulfoxide; EDTA: Ethylenediaminetetraacetic acid; DMEM: Dulbecco's modified eagle medium; DAPI: 4,6-Diamino-2-phenyl indole; ${ }^{1}$ H NMR: Proton nuclear magnetic resonance; UV-Vis: Ultraviolet-visible spectroscopy; TEM: Transmission electron microscopy; DLS: Dynamic light scattering; WBC: White blood cells; RBC: Red blood cells; HGB: Hemoglobin; $\mathrm{MCH}$ : Means corpuscular hemoglobin; LYN: Lymphocytes percentage; HCT: Hematocrit; MCV: Means corpuscularvolume; MCHC: Means corpuscular hemoglobin concentration; PLT: Platelets; MON: Monocyte; GRAN: Granulocyte; ALT: Alanine aminotransferase; AST: Aspartate aminotransferase; UREA: Urea; UA: Uric acid; CREA: Creatinine.

\section{Supplementary Information}

The online version contains supplementary material available at https://doi. org/10.1186/s12951-022-01247-6.

Additional file 1: Table S1. The TPZ drug loading content (LC \%) and entrapment efficiency (EE \%) of GPPCT and GmPCT. Table S2. The hydrodynamic diameters, polydispersity index and Zeta potential of GPP, GmP, GPPC, GmPC, GPPCT and GmPCT. Table S3. IC $C_{50}$ value and safety index 
of GPPCT for different cells. Fig. S1. The action mechanism of TPZ under normal and hypoxic conditions. Fig. S2. ${ }^{1} \mathrm{H}$ NMR spectra of (a) PBA-PEG$\mathrm{COOH}$, (b) G5. $\mathrm{NH}_{2}$-PEG-PBA, (c) G5.NH 2 -mPEG and (d) G5.NHAc-mPEG. Fig. S3. Schematic diagram of the synthesis of G5.NHAc-mPEG@Cu(II)/TPZ (GmPCT). Fig. S4. The UV-vis spectra of GmP, GmPC, GmPCT, $\mathrm{CuCl}_{2}$ and TPZ. Fig. S5. (a) TEM image and (b) size distribution histograms of GMPCT. Fig. S6. Hydrodynamic diameter histogram of GPPCT and GmPCT. Fig. S7. Changes of hydrodynamic diameters and Zeta potential of $(a, b)$ GPPCT and (c, d) GMPCT in water, PBS and DMEM medium for 1, 3, 5 and 7 days. Fig. S8. (a) Accumulative release of TPZ from GPPCT in buffer solutions with different $\mathrm{pH}$ of $5.5,6.5$ and 7.4 at $37{ }^{\circ} \mathrm{C}([\mathrm{GPPCT}]=1 \mathrm{mg} / \mathrm{mL})$. (b) UV-vis spectra of MB treated with $\mathrm{H}_{2} \mathrm{O}_{2}$ and TPZ with or without the presence of GSH for $4 \mathrm{~h}$ ([TPZ] $=200 \mu \mathrm{M})$. Fig. S9. (a) CCK-8 assay of $4 \mathrm{~T} 1$ cells under different concentrations of $\mathrm{CoCl}_{2} \cdot \mathrm{H}_{2} \mathrm{O}$ in the presence or absence of GPPCT ([TPZ] $=2.5 \mu \mathrm{M})$. (b) HIF-1a expression of $4 \mathrm{~T} 1$ cells in the presence or absence of $\mathrm{CoCl}_{2} \cdot \mathrm{H}_{2} \mathrm{O}$ determined by western blot and (c) its quantitative analysis results $\left(\left[\mathrm{COCl}_{2} \cdot \mathrm{H}_{2} \mathrm{O}\right]=100 \mu \mathrm{M}\right)$. Fig. $\mathbf{S 1 0}$. Cell viability of 4T1 (hypoxia and normoxia) and L929 (normoxia) cells after co-culture with GPP detected by CCK-8 assay. Fig. S11. $m$ Cell viability of (a) L929 cells and (b) normoxic 4T1 cells after co-culture with free TPZ, GPPC, GPPCT and GmPCT for $24 \mathrm{~h}$ detected by CCK-8 assay. Fig. S12. Representative images of tumor bearing mice with different treatments on the 20th days posttreatment. (1: PBS, 2: GPP, 3: TPZ, 4: GPPC, 5: GMPCT and 6: GPPCT.). Fig. S13. Quantification of (a) TUNEL mean fluorescence intensity, (b) positive signals of Ki-67, (c) HIF-1a and (d) DHE mean fluorescence intensity after different treatments. ${ }^{* * *} p<0.001$. Fig. S14. Blood biochemistry analysis of (a) WBC, (b) RBC, (c) HGB, (d) MCH, (e) LYM, (f) HCT, (g) MCV, (h) MCHC, (i) PTL, (j) MON and (k) GRAN of mice on the last day of different treatments of (I) PBS and (II) GPPCT. Liver function index of (I) ALT and (m) AST and kidney function index of (n) UREA, (o) UA and (p) CREA of mice on the last day of with different treatments of (I) PBS and (II) GPPCT $(n=3)$.

\section{Acknowledgements}

Not applicable.

\section{Authors' contributions}

YH and RG designed the study. YH did most of the experiments, analyzed the data, organized the data, and wrote the manuscript. YF contributed to the study design. $C Z$ and $M Z$ assist in animal experiments. $Y G$ and $R G$ revised the manuscript. RG, XS and XC supervised the work. RG and XS provided financial support. All authors read and approved the final manuscript.

\section{Funding}

This work is financially supported by the National Natural Science Foundation of China (21875031 and 81761148028 ), Shanghai Talent Development Fund (2019115), and the Science and Technology Commission of Shanghai Municipality (19XD1400100, 19PJD001, 21490711500, 20DZ2254900).

\section{Availability of data and materials}

All data analyzed during this study are included in this published article and its supplementary information files.

\section{Declarations}

\section{Ethics approval and consent to participate}

All animal experiments were performed in accordance with the guidelines from the Institutional Committee for Animal Care and Use of Donghua University and also with the regulations of the National Ministry of Health.

\section{Consent for publication}

All authors read and agreed to publish the manuscript.

\section{Competing interests}

The authors declare no conflict of interest.

Received: 9 November 2021 Accepted: 4 January 2022

Published online: 21 January 2022

\section{References}

1. Zhang L, Fan Y, Yang Z, Yang M, Wong C-Y. NIR-II-driven and glutathione depletion-enhanced hypoxia-irrelevant free radical nanogenerator for combined cancer therapy. J Nanobiotechnol. 2021;19:265.

2. Tang Z, Liu Y, He M, Bu W. Chemodynamic therapy: tumour microenvironment-mediated fenton and fenton-like reactions. Angew Chem Int Ed. 2019;58:946-56.

3. Zhang C, Bu W, Ni D, Zhang S, Li Q, Yao Z, Zhang J, Yao H, Wang Z, Shi J. Synthesis of iron nanometallic glasses and their application in cancer therapy by a localized fenton reaction. Angew Chem Int Ed. 2016;55:2101-6.

4. Sun Y, Li Y, Shi S, Dong C. Exploiting a new approach to destroy the barrier of tumor microenvironment: nano-architecture delivery systems. Molecules. 2021;26:2703.

5. Wu P, Gao W, Su M, Nice EC, Zhang W, Lin J, Xie N. Adaptive mechanisms of tumor therapy resistance driven by tumor microenvironment. Front Cell Dev Biol. 2021;9:357.

6. Wiggins JM, Opoku-Acheampong AB, Baumfalk DR, Siemann DW, Behnke BJ. Exercise and the tumor microenvironment: potential therapeutic implications. Exerc Sport Sci Rev. 2018. https://doi.org/10.1249/JES.00000 00000000137.

7. Kumari S, Advani D, Sharma S, Ambasta RK, Kumar P. Combinatorial therapy in tumor microenvironment: where do we stand? Biochim Biophys Acta BBA Rev Cancer. 2021;1876: 188585.

8. Zheng M, Liu Y, Wang Y, Zhang D, Zou Y, Ruan W, Yin J, Tao W, Park JB, Shi B. ROS-responsive polymeric siRNA nanomedicine stabilized by triple interactions for the robust glioblastoma combinational RNAi therapy. Adv Mater. 2019;31:1903277.

9. Tang G, He J, Liu J, Yan X, Fan K. Nanozyme for tumor therapy: surface modification matters. Exploration. 2021;1:75-89.

10. Xia X, Shi B, Wang L, Liu Y, Zou Y, Zhou Y, Chen Y, Zheng M, Zhu Y, Duan J, et al. From mouse to mouse-ear cress: nanomaterials as vehicles in plant biotechnology. Exploration. 2021;1:9-20.

11. Ma B, Wang S, Liu F, Zhang S, Duan J, Li Z, Kong Y, Sang Y, Liu H, Bu W, Li L. Self-assembled copper-amino acid nanoparticles for in situ glutathione "AND" $\mathrm{H}_{2} \mathrm{O}_{2}$ sequentially triggered chemodynamic therapy. J Am Chem Soc. 2019;141:849-57.

12. Lin LS, Huang T, Song JB, Ou XY, Wang ZT, Deng HZ, Tian R, Liu YJ, Wang $J$ F, Liu Y, et al. Synthesis of copper peroxide nanodots for $\mathrm{H}_{2} \mathrm{O}_{2}$ selfsupplying chemodynamic therapy. J Am Chem Soc. 2019;141:9937-45.

13. Liang K, Sun H, Yang Z, Yu H, Shen J, Wang X, Chen H. Breaking the redox homeostasis: an albumin-based multifunctional nanoagent for GSH depletion-assisted chemo-/chemodynamic combination therapy. Adv Func Mater. 2021;31:2100355.

14. Wang Y, Zhang S, Wang J, Zhou Q, Mukerabigwi JF, Ke W, Lu N, Ge Z. Ferrocene-containing polymersome nanoreactors for synergistically amplified tumor-specific chemodynamic therapy. J Control Release. 2021;333:500-10.

15. Silva VL, Kaassis A, Dehsorkhi A, Koffi C-R, Severic M, Abdelhamid M, Nyimanu D, Morris CJ, Al-Jamal WT. Enhanced selectivity, cellular uptake, and in vitro activity of an intrinsically fluorescent copper-tirapazamine nanocomplex for hypoxia targeted therapy in prostate cancer. Biomater Sci. 2020;8:2420-33.

16. Chen X, Zhang H, Zhang M, Zhao P, Song R, Gong T, Liu Y, He X, Zhao K, Bu W. Amorphous Fe-based nanoagents for self-enhanced chemodynamic therapy by re-establishing tumor acidosis. Adv Func Mater. 2020;30:1908365.

17. Zhao P, Tang Z, Chen X, He Z, He X, Zhang M, Liu Y, Ren D, Zhao K, Bu W. Ferrous-cysteine-phosphotungstate nanoagent with neutral $\mathrm{pH}$ fenton reaction activity for enhanced cancer chemodynamic therapy. Mater Horiz. 2019;6:369-74.

18. Cao S, Fan J, Sun W, Li F, Li K, Tai X, Peng X. A novel Mn-Cu bimetallic complex for enhanced chemodynamic therapy with simultaneous glutathione depletion. Chem Commun. 2019;55:12956-9.

19. Huang H, Dong C, Chang M, Ding L, Chen L, Feng W, Chen Y. Mitochondria-specific nanocatalysts for chemotherapy-augmented sequential chemoreactive tumor therapy. Exploration. 2021;1:50-60.

20. Tang W, Gao H, Ni D, Wang Q, Gu B, He X, Peng W. Bovine serum albumintemplated nanoplatform for magnetic resonance imaging-guided chemodynamic therapy. J Nanobiotechnol. 2019;17:68. 
21. Erra Díaz F, Dantas E, Geffner J. Unravelling the interplay between extracellular acidosis and immune cells. Mediat Inflamm. 2018;2018:1218297.

22. Zhao $\mathrm{H}$, Wang $\mathrm{Y}$, Wang $\mathrm{Y}$, Cao $\mathrm{T}$, Zhao G. Electro-fenton oxidation of pesticides with a novel $\mathrm{Fe}_{3} \mathrm{O}_{4} @ \mathrm{Fe}_{2} \mathrm{O}_{3}$ /activated carbon aerogel cathode: high activity, wide $\mathrm{pH}$ range and catalytic mechanism. Appl Catal, B. 2012;125:120.

23. Brillas E, Baños MA, Camps S, Arias C, Cabot PL, Garrido JA, Rodríguez RM. Catalytic effect of $\mathrm{Fe}^{2+}, \mathrm{Cu}^{2+}$ and UVA light on the electrochemical degradation of nitrobenzene using an oxygen-diffusion cathode. $\mathrm{N} \mathrm{J} \mathrm{Chem.}$ 2004;28:314-22.

24. Fan Y, Zhang J, Shi M, Li D, Lu C, Cao X, Peng C, Mignani S, Majoral J-P, Shi X. Poly(amidoamine) dendrimer-coordinated copper(II) complexes as a theranostic nanoplatform for the radiotherapy-enhanced magnetic resonance imaging and chemotherapy of tumors and tumor metastasis. Nano Lett. 2019;19:1216-26.

25. Shannon AM, Bouchier-Hayes DJ, Condron CM, Toomey D. Tumour hypoxia, chemotherapeutic resistance and hypoxia-related therapies. Cancer Treat Rev. 2003;29:297-307.

26. Arthur-Baidoo E, Ameixa J, Ziegler P, Ferreira da Silva F, Ončák M, Denifl $S$. Reactions in tirapazamine induced by the attachment of low-energy electrons: dissociation versus roaming of $\mathrm{OH}$. Angew Chem Int Ed. 2020;59:17177-81.

27. LiY, Sutrisno L, Hou Y, Fei Y, Xue C, Hu Y, Li M, Luo Z. A redox-activatable biopolymer-based micelle for sequentially enhanced mitochondriatargeted photodynamic therapy and hypoxia-dependent chemotherapy. Chem Commun. 2020;56:9978-81.

28. Zhang R, Feng LZ, Dong ZL, Wang L, Liang C, Chen JW, Ma QX, Zhang R, Chen Q, Wang YC, Liu Z. Glucose and oxygen exhausting liposomes for combined cancer starvation and hypoxia-activated therapy. Biomaterials. 2018;162:123-31.

29. Phillips RM. Targeting the hypoxic fraction of tumours using hypoxiaactivated prodrugs. Cancer Chemother Pharmacol. 2016;77:441-57.

30. Insanullah KM, Kumar BN, Zhao Y, Muhammad H, Liu Y, Wang L, Liu H, Jiang W. Stepwise-activatable hypoxia triggered nanocarrier-based photodynamic therapy for effective synergistic bioreductive chemotherapy. Biomaterials. 2020;245: 119982.

31. Xin J, Deng C, Aras O, Zhou M, Wu C, An F. Chemodynamic nanomaterials for cancer theranostics. J Nanobiotechnol. 2021;19:192.

32. Cao W, Jin M, Yang K, Chen B, Xiong M, Li X, Cao G. Fenton/Fenton-like metal-based nanomaterials combine with oxidase for synergistic tumor therapy. J Nanobiotechnol. 2021;19:325.

33. Lee HR, Leslie F, Azarin SM. A facile in vitro platform to study cancer cell dormancy under hypoxic microenvironments using $\mathrm{CoCl}_{2}$.J Biol Eng. 2018;12:12.

34. Sarlauskas J, Nemeikaite-Ceniene A, Maroziene A, Miseviciene L, Lesanavicius $\mathrm{M}$, Cenas N. Enzymatic single-electron reduction and aerobic cytotoxicity of tirapazamine and its 1-oxide and nor-oxide metabolites. Chemija. 2018;29:273-80.

35. Li Y, Zhao L, Li XF. Targeting hypoxia: hypoxia-activated prodrugs in cancer therapy. Front Oncol. 2021;11:700407.

36. Hellauer K, Lesage G, Sdicu AM, Turcotte B. Large-scale analysis of genes that alter sensitivity to the anticancer drug tirapazamine in Saccharomyces cerevisiae. Mol Pharmacol. 2005:68:1365-75.

37. Peters KB, Brown JM. Tirapazamine: a hypoxia-activated topoisomerase II poison. Cancer Res. 2002;62:5248-53.

38. Wang J, Wang Z, Zhong Y, Zou Y, Wang C, Wu H, Lee A, Yang W, Wang X, Liu Y, et al. Central metal-derived co-assembly of biomimetic GdTPP/ ZnTPP porphyrin nanocomposites for enhanced dual-modal imagingguided photodynamic therapy. Biomaterials. 2020;229: 119576.

39. Wang X, Wang J, Wang J, Zhong Y, Han L, Yan J, Duan P, Shi B, Bai F. Noncovalent self-assembled smart gold(III) porphyrin nanodrug for synergistic chemo-photothermal therapy. Nano Lett. 2021;21:3418-25.

\section{Publisher's Note}

Springer Nature remains neutral with regard to jurisdictional claims in published maps and institutional affiliations.

Ready to submit your research? Choose BMC and benefit from:

- fast, convenient online submission

- thorough peer review by experienced researchers in your field

- rapid publication on acceptance

- support for research data, including large and complex data types

- gold Open Access which fosters wider collaboration and increased citations

- maximum visibility for your research: over $100 \mathrm{M}$ website views per year

At BMC, research is always in progress.

Learn more biomedcentral.com/submissions 